\title{
Multidecadal Warming and Shoaling of Antarctic Intermediate Water*
}

\author{
SUNKE SCHMIDTKO AND GREGORY C. JOHNSON \\ National Oceanic and Atmospheric Administration/Pacific Marine Environmental Laboratory, Seattle, Washington
}

(Manuscript received 5 January 2011, in final form 5 May 2011)

\begin{abstract}
Antarctic Intermediate Water (AAIW) is a dominant Southern Hemisphere water mass that spreads from its formation regions just north of the Antarctic Circumpolar Current (ACC) to at least $20^{\circ} \mathrm{S}$ in all oceans. This study uses an isopycnal climatology constructed from Argo conductivity-temperature-depth (CTD) profile data to define the current state of the AAIW salinity minimum (its core) and thence compute anomalies of AAIW core pressure, potential temperature, salinity, and potential density since the mid-1970s from shipbased CTD profiles. The results are used to calculate maps of temporal property trends at the AAIW core, where statistically significant strong circumpolar shoaling $\left(30-50 \mathrm{dbar}^{\mathrm{decade}} \mathrm{e}^{-1}\right)$, warming $\left(0.05^{\circ}-0.15^{\circ} \mathrm{C}\right.$ decade $\left.{ }^{-1}\right)$, and density reductions [up to $-0.03\left(\mathrm{~kg} \mathrm{~m}^{-3}\right) \mathrm{decade}^{-1}$ ] are found. These trends are strongest just north of the ACC in the southeast Pacific and Atlantic Oceans and decrease equatorward. Salinity trends are generally small, with their sign varying regionally. Bottle data are used to extend the AAIW core potential temperature anomaly analysis back to 1925 in the Atlantic and to 1960 elsewhere. The modern warm AAIW core conditions appear largely unprecedented in the historical record: biennially and zonally binned median AAIW core potential temperatures within each ocean basin are, with the notable exception of the subtropical South Atlantic in the $1950 \mathrm{~s}-70 \mathrm{~s}, 0.2-1^{\circ} \mathrm{C}$ colder than modern values. Zonally averaged sea surface temperature anomalies around the AAIW formation latitudes in each ocean and sectoral southern annular mode indices are used to put the AAIW core property trends and variations into context.
\end{abstract}

\section{Introduction}

Antarctic Intermediate Water (AAIW) is a very prominent water mass that lies above the deep water and spreads below the subtropical thermocline in the Southern Hemisphere. AAIW has long been identified by a pronounced salinity minimum from $600-$ to $1000-\mathrm{m}$ depth (Wüst 1936, 1-288) found north of the Antarctic Circumpolar Current (ACC) in all three oceans (Fig. 1). McCartney (1977) suggested that AAIW is formed primarily in the southeast Pacific Ocean just equatorward of the ACC, as the coldest and freshest variety of Subantarctic Mode Water (SAMW). Molinelli (1981) suggested that cold fresh surface waters flow northward across the ACC to contribute to the AAIW salinity

* Pacific Marine Environmental Laboratory Contribution Number 3657.

Corresponding author address: Sunke Schmidtko, University of East Anglia, School of Environmental Sciences, Norwich NR4 7TJ, United Kingdom.

E-mail: s.schmidtko@uea.ac.uk minimum, primarily in the Indian Ocean near Kerguelen Island and in the southeast Pacific Ocean. Piola and Georgi (1982) argued that both mechanisms contribute to AAIW formation regionally (the former in the southeast Pacific and the latter in the South Atlantic) and noted prominent AAIW property variations among all three oceans.

After formation near its proposed main creation regions in the South Atlantic (Talley 1996) and southeast Pacific Oceans (Taft 1963), AAIW spreads northward (Fig. 1). Even in the Indian Ocean, with only limited AAIW ventilation (Fine 1993), a distinct AAIW salinity minimum is found from the ACC to the latitude of the Indonesian Throughflow (Fig. 1). Around $20^{\circ} \mathrm{S}$, salty subtropical surface waters start to have a significant impact on AAIW characteristics, especially in the Indian and Pacific Oceans, where the density of the salinity minimum associated with AAIW increases markedly north of $20^{\circ} \mathrm{S}$. In the Atlantic the AAIW salinity minimum persists to at least $20^{\circ} \mathrm{N}$ (Fig. 1), with northward spreading intensified at the western boundary in the subtropics (Defant 1941, 191-260; Taft 1963). The silicic-acid-rich characteristics of AAIW can even be followed along the 
a) $25^{\circ} \mathrm{W}$ section

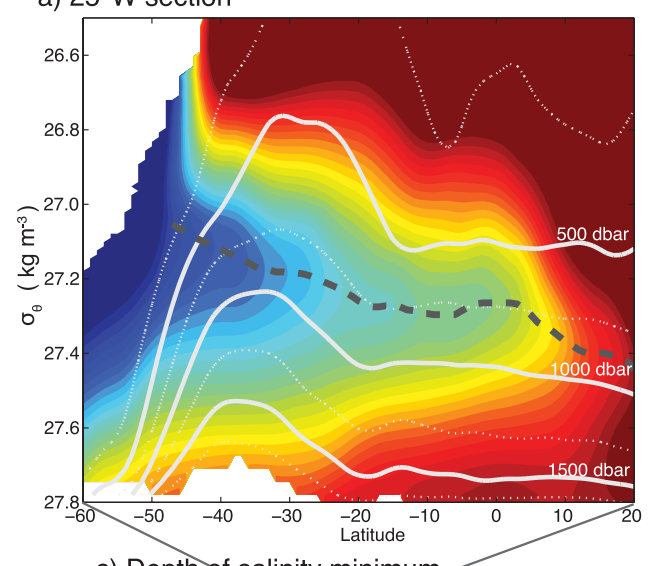

b) $85^{\circ}$ E section

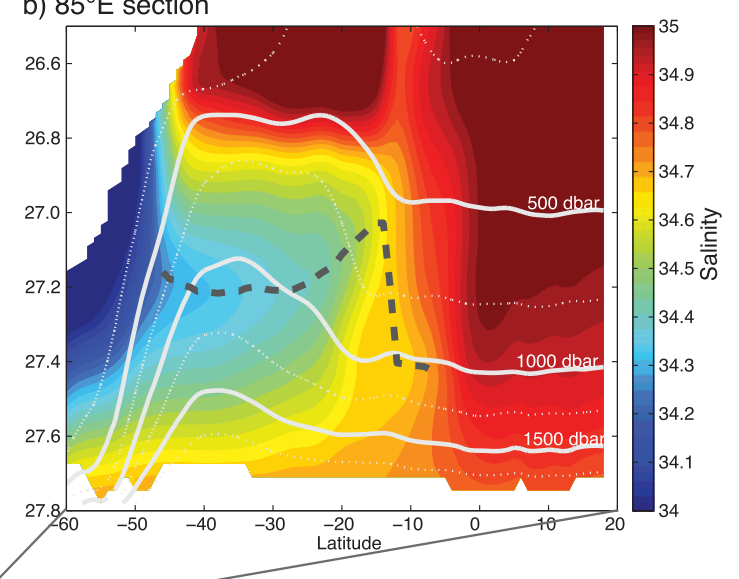

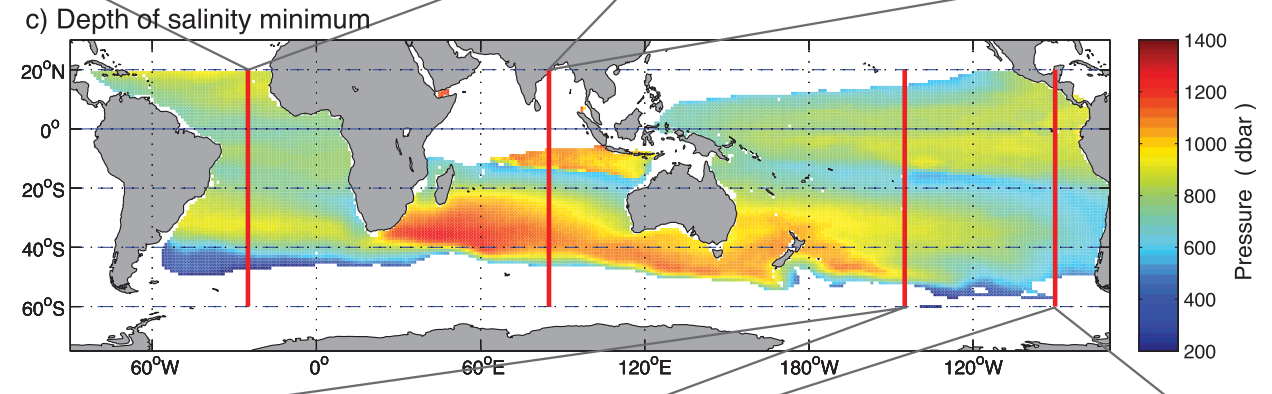

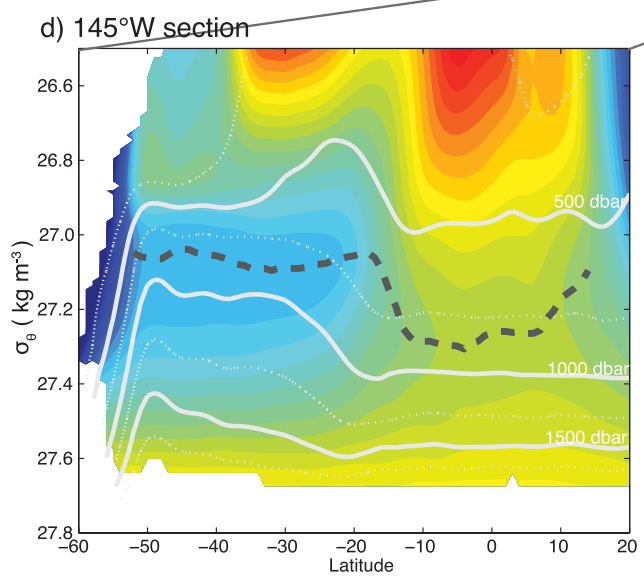

e) $90^{\circ} \mathrm{W}$ section

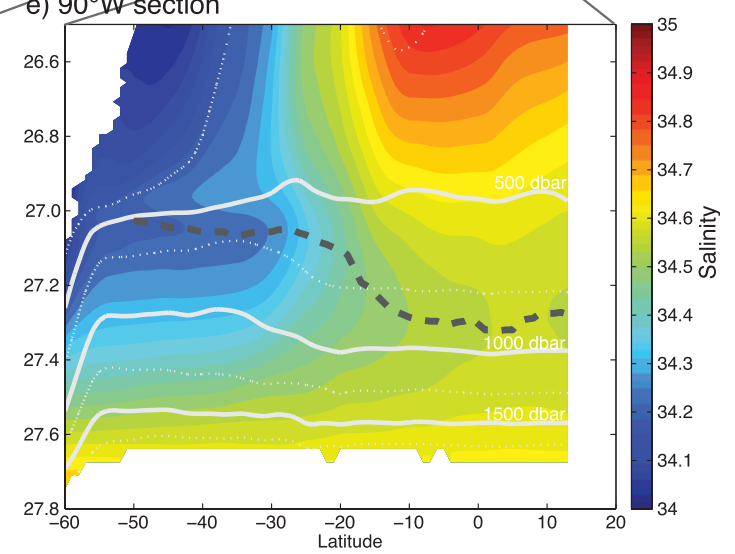

FIG. 1. Meridional-vertical sections of Argo float climatology salinity (colors) and pressure at 500-dbar intervals (thick solid white lines) as well as intermediate 250-dbar intervals (thin dotted white lines) with a vertical axis of potential density in the (a) Atlantic, (b) Indian, and (d),(e) Pacific Oceans. The AAIW core (salinity minimum) is also indicated (thick dashed gray lines). (c) Argo climatology AAIW core pressure (colors) south of $20^{\circ} \mathrm{N}$ with section locations indicated (red lines).

Gulf Stream and the North Atlantic Current all the way to $60^{\circ} \mathrm{N}$ (Tsuchiya 1989).

There have been many investigations, both regional and global, into intermediate-depth potential temperature and salinity changes on isobars and isopycnals in the southern oceans (Bindoff and Church 1992; Johnson and Orsi 1997; Bindoff and McDougall 2000; Wong et al. 2001; Arbic and Owens 2001; Aoki et al. 2005; McDonagh et al. 2005; Böning et al. 2008; Durack and Wijffels 2010; Helm et al. 2010; McCarthy et al. 2011). These studies almost uniformly find warming and salinification with passing time on isopycnals denser than the AAIW salinity minimum and usually (although not always) note a cooling and freshening over time on lighter isopycnals. This isopycnal cooling and freshening above the AAIW and warming and salinification below form a dipole around the core of the AAIW. It is not clear from climate model diagnoses whether this pattern can be attributed to climate change (Stark et al. 2006). However, the pattern is consistent with an overall warming of AAIW salinity minimum, as discussed below. 
Here we take a global and phenomenological approach to analyze observed hydrographic changes at the core of the AAIW, defined by its local vertical salinity minimum. In recent years the Argo Program array of conductivitytemperature-depth (CTD) instrument-carrying profiling floats has provided, for the first time, year-round data from the undersampled regions in the Southern Hemisphere oceans. The continuously improving data coverage there allows insights into AAIW formation and spreading, as well as variability and trends of potential temperature and salinity. Comparing historical ship-based CTD data to Argo CTD data, we find that since the mid1970s the AAIW core warms $0.05^{\circ}-0.15^{\circ} \mathrm{C}$ decade $^{-1}$, shoals 30-50 dbar decade ${ }^{-1}$, and shifts appreciably toward lighter densities, with magnitudes of these changes depending on ocean basin. Salinity trends at the AAIW core vary regionally in both sign and magnitude. Using bottle station data back to the mid-1920s reveals that the AAIW core warming is multidecadal, with modern conditions apparently largely unprecedented in the historical record.

\section{Data and methods}

We construct a modern-time-period isopycnal climatology from Argo float CTD data, analyze AAIW structure with it, and use it as a reference from which to compute anomalies of potential temperature $(\theta)$, salinity $(S)$, pressure $(P)$, and potential density $\left(\sigma_{\theta}\right)$ at the AAIW salinity minimum (the AAIW core) from ship-based CTD profiles since the mid-1970s and AAIW core anomalies in $\theta$ only from bottle data profiles from the mid-1920s through the early 1980s.

The Argo float climatology uses all available quality controlled Argo float CTD data flagged as good through March 2010. We use delayed-mode quality controlled data as available and real-time quality controlled data for profiles on which delayed-mode processing has not yet been completed. For all individual float profiles, $\theta, S$, and $P$ are interpolated onto $\sigma_{\theta}$ levels for $26.6<\sigma_{\theta}<$ $27.6 \mathrm{~kg} \mathrm{~m}^{-3}$ at $0.009-0.013 \mathrm{~kg} \mathrm{~m}^{-3}$ intervals that decrease with increasing density. Closer to the surface, for $\sigma_{\theta}<$ $26.6 \mathrm{~kg} \mathrm{~m}^{-3}$, the intervals of $\Delta \sigma_{\theta}$ are on the order of $0.05-0.09 \mathrm{~kg} \mathrm{~m}^{-3}$ and on the order of $0.03 \mathrm{~kg} \mathrm{~m}^{-3}$ for $\sigma_{\theta}>27.6 \mathrm{~kg} \mathrm{~m}^{-3}$.

We construct a modern $\theta, S$, and $P$ climatology by mapping the Argo CTD data to a $1^{\circ}$ latitude $\times 1^{\circ}$ longitude $\times$ four-season grid (regardless of year) on each isopycnal level using a locally weighted scatterplot smoother (LOESS; Cleveland and Devlin 1988) that fits a quadratic surface to nearby data using weighted least squares. The temporal radius of the fit is 3 months, and the horizontal radii are adaptive. The zonal radius is twice that of the meridional radius, owing to the strong zonal nature of features in the interior of the Southern Ocean, although this choice slightly smears out the mapped fields near eastern and western boundaries. The mapping uses the closest 4000 data points, with a $500-\mathrm{km}$ lower threshold for the meridional radius, expanding to an $825-\mathrm{km}$ upper threshold as necessary to reach (or approach in very data-sparse regions) the 4000-data-point target. These choices provide around 1000 data points close in space and time for each of the four seasons, allowing a smooth, well-mapped climatology.

As a last step prior to mapping, an interquartile range (IQR) filter is applied at each grid point to the selected $S$ and $P$ data, rejecting values that are 3 times the IQR below the first quartile or 3 times the IQR above the third quartile. Because the analysis is isopycnal, applying this quality control filter to $\theta$ would be redundant with regard to its application to $S$.

After mapping we compute annual means of $\theta, S$, and $P$ as the time means of the four seasonal maps for each quantity on each isopycnal, only considering density levels with a year-round presence at each geographical location. Mapping seasonally and then averaging the four seasons significantly reduces noise present in the individual seasonal maps and also minimizes any residual seasonal sampling bias. Data points within the climatology with standard errors above $15 \mathrm{dbar}$ in $P, 0.2^{\circ} \mathrm{C}$ in $\theta$, or 0.06 PSS-78 (practical salinity scale 1978) in $S$ are removed.

The reference AAIW core used in this study is defined as the local vertical salinity minimum found for $26.98<$ $\sigma_{\theta}<27.8 \mathrm{~kg} \mathrm{~m}^{-3}$ at each grid point of the Argo float climatology between $60^{\circ} \mathrm{S}$ and $20^{\circ} \mathrm{N}$. This density range exceeds that of the AAIW core for all but the far northern reaches of that feature in the Atlantic Ocean, likely covering all AAIW formed within the decades of observational data used in this study. Seasonal cycles of properties of the AAIW core are smaller than the noise except for AAIW core $P$ within $\sim 200 \mathrm{~km}$ of its southernmost extent, motivating our averaging of the seasonal maps as detailed above.

Ship-based CTD data used in this study (Fig. 2) encompass all profiles in the HydroBase2 database (Lozier et al. 1995; information available online at http:// www.whoi.edu/science/PO/hydrobase/) available as of November 2008 and all Climate Variability and Predictability (CLIVAR) and the Carbon Hydrographic Data Office (CCHDO) database sections available in netCDF format as of October 2010 that extend south of the equator (212 sections, including repeat sections). All data flagged as bad or probably bad are discarded. To prevent those data available in both datasets from being used twice, all HydroBase 2 profiles found within $10 \mathrm{~km}$ and $24 \mathrm{~h}$ of any CCHDO profile are treated as duplicates 
a) data distribution 1970-1979

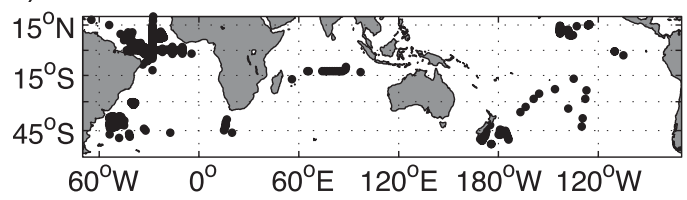

C) data distribution 1990-1999

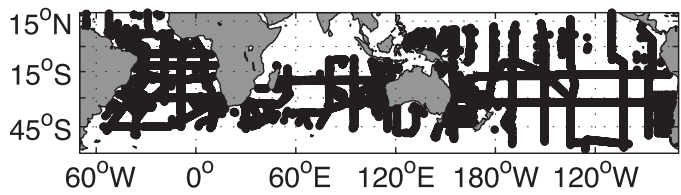

b) data distribution 1980-1989

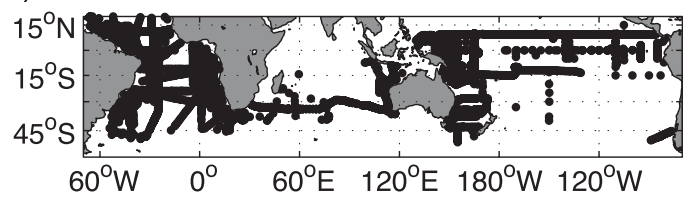

d) data distribution since 2000

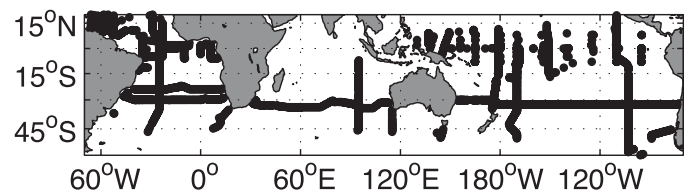

FIG. 2. CTD station locations with a salinity minimum within the range $26.98<\sigma_{\theta}<27.8 \mathrm{~kg} \mathrm{~m}^{-3}$ by decade.

and discarded. Further quality control criteria for ship-based CTD profiles include a minimum vertical resolution of $12 \mathrm{dbar}$ and a maximum pressure exceeding 1300 dbar.

The AAIW core for each ship-based CTD profile is determined similarly to that in the Argo float climatologyas the local vertical salinity minimum found within $26.98<$ $\sigma_{\theta}<27.8 \mathrm{~kg} \mathrm{~m}^{-3}$. Anomalies of $\theta, S, P$, and $\sigma_{\theta}$ at the AAIW core for that profile are then determined with respect to the Argo climatology by taking the differences between these parameters at the AAIW core for each CTD profile and those for the Argo float climatology AAIW core interpolated to the position of the CTD profile.

For mapping the larger-scale trends of the anomalies of the CTD data from the Argo climatology we use LOWESS (a weighted least squares planar fit to local data) with a $1500-\mathrm{km}$ radius. The use of a weighted planar LOWESS fit (instead of a weighted quadratic LOESS fit) and a larger smoothing radius better suits the CTD data distribution (Fig. 2), which is sparser than the distribution of Argo data used for the climatology. This stronger smoothing is acceptable since spatial variations of AAIW core properties are removed by defining the anomalies as departures from the well-resolved, locally representative climatology. As a last step prior to trend computation and mapping the data are quality controlled by an IQR filter applied to $\theta$ and $\sigma_{\theta}$ anomalies, rejecting values twice the IQR below the first quartile or twice the IQR above the third quartile. This interval covers $>99.9 \%$ of a normal distribution.

We calculate the trend and its standard error by applying LOWESS as mentioned above to nearby shipbased CTD-derived anomalies. We also include the value from the Argo climatology at the grid point being mapped, which by definition has anomalies of zero for each parameter. We use a date of January 2009 for each Argo climatology value and assign it a weight of 50 to reflect the large number of float profiles used in its estimation. This weight roughly corresponds to that which would accrue to data from one hydrographic section crossing the grid point in question with profiles spaced at 10-nautical-mile intervals, much closer spacing than most open-ocean CTD surveys.

Historical bottle casts are often sparsely spaced in the vertical, and hydrographic stations are also laterally very sparse and irregular prior to the 1950s. Nonetheless, the AAIW core $\theta$ anomalies can be determined with errors smaller than the observed anomalies. Therefore, we analyze their biennial arithmetic means and medians for each ocean basin in two distinct latitude bands using bottle data from 1925 through 1981. Hydrographic data prior to 1925 are so vertically sparse that they do not pass the analysis and quality control procedures described below.

While multiple bottle casts are often taken at a single station, the data are stored as individual casts, each with a relatively small number of data points, often between 12 and 24. Thus we analyze these data using a threedimensional LOESS smoother with $\theta$ as the vertical axis. We construct profiles of $S$ versus $\theta$ for the years from 1925 to 1980 on a $1^{\circ}$ latitude $\times 1^{\circ}$ longitude $\times 1$ yr grid between $50^{\circ}$ and $20^{\circ} \mathrm{S}$ for each point that has data within $0.71^{\circ}$ latitude and $0.5 \mathrm{yr}$. The $\theta$ grid ranges from $2.9^{\circ}$ to $5.7^{\circ} \mathrm{C}$ in $0.02^{\circ} \mathrm{C}$ steps. The LOESS smoother uses radii of $2^{\circ}$ latitudinal distance, $3 \mathrm{yr}$, and $0.2^{\circ} \mathrm{C}$, only accepting data points within the density range of the AAIW core $\left(26.98<\sigma_{\theta}<27.8 \mathrm{~kg} \mathrm{~m}^{-3}\right)$ and from stations in water depth $>3000 \mathrm{~m}$.

Salinity values are only retained if the summed weights exceed unity. Profiles with less than $2 / 3$ of grid points retained from $2.9^{\circ}-5.7^{\circ} \mathrm{C}$ are discarded. This situation can occur if only shallow data are available or bottle data are too sparse vertically. For each profile the AAIW core is determined and the value of $\theta$ there is compared to that of the Argo float climatology at that location to determine the local AAIW core $\theta$ anomaly. Bottle data between Madagascar and Africa are not analyzed because of poor representation of that region in the Argo climatology. The error for an individual derived AAIW core $\theta$ anomaly by 
a) $45^{\circ} \mathrm{S} 30.25^{\circ} \mathrm{W}$
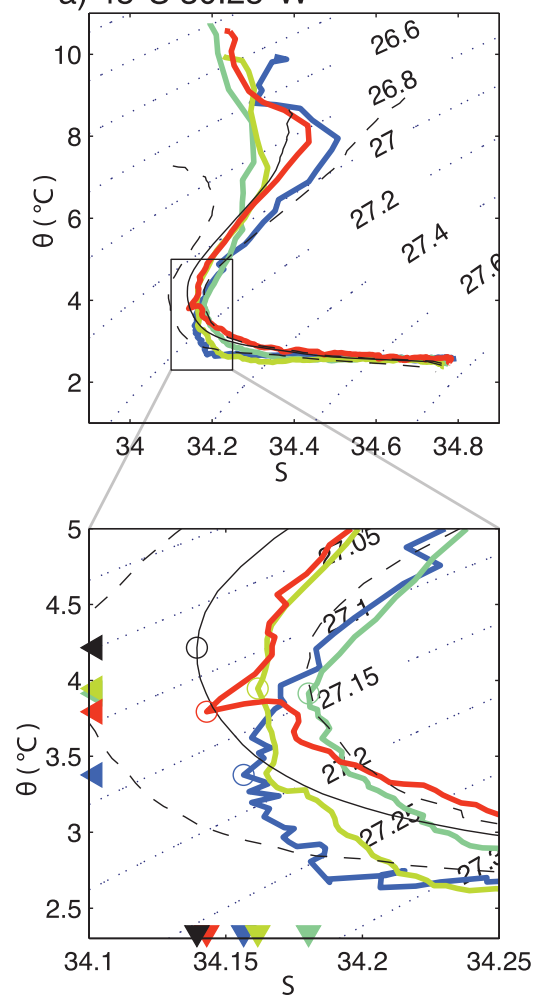

b) $32.5^{\circ} \mathrm{S} 88.5^{\circ} \mathrm{W}$
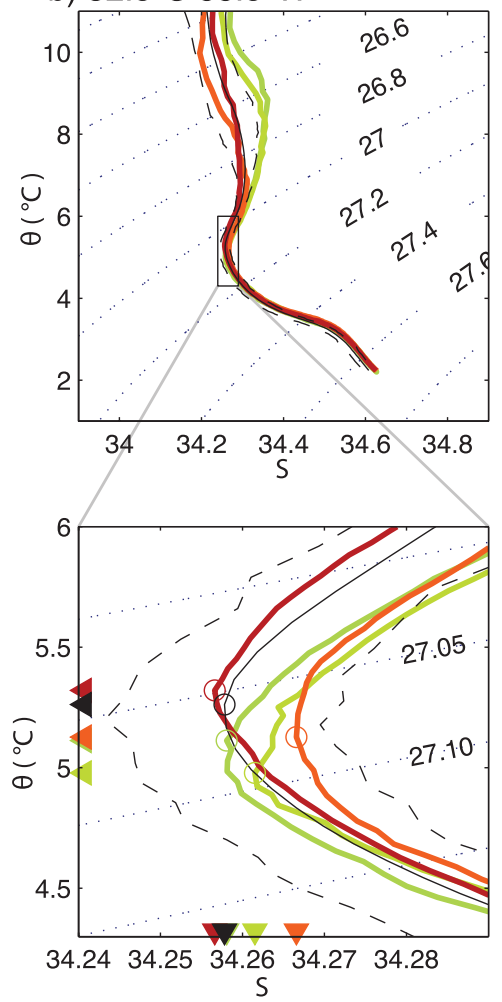

c) $48.5^{\circ} \mathrm{S} 88.25^{\circ} \mathrm{W}$
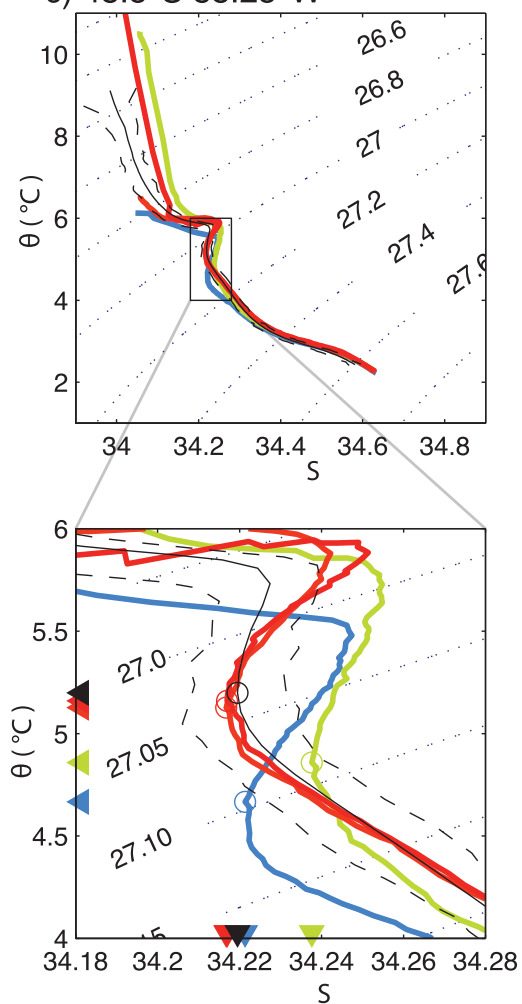

climatology

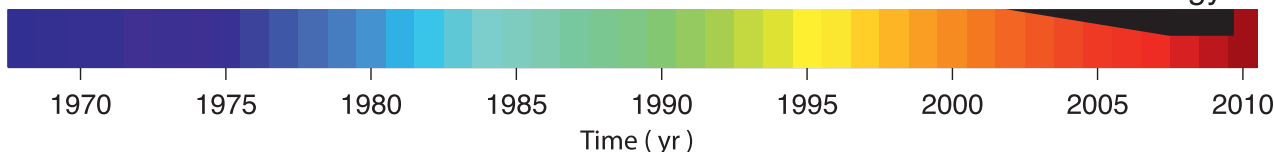

FIG. 3. CTD station $\theta-S$ curves color-coded by age for relatively frequently sampled areas in the (a) South Atlantic and (b),(c) South Pacific Oceans with a focus on the AAIW core (salinity minimum, circled) in the bottom figures. Argo float climatology $\theta-S$ curves (solid black lines) are shown with one standard deviation $S$ envelopes (dashed black lines). AAIW core $\theta$ and $S$ values color-coded by age are marked (triangles) on the left and bottom axes of the lower figures, respectively, with Argo climatology values in black. Potential density contours (dotted gray lines) are overlaid at (top) $0.2 \mathrm{~kg} \mathrm{~m}^{-3}$ and (bottom) $0.05 \mathrm{~kg} \mathrm{~m}^{-3}$ intervals. Lower figure scales vary.

this method is strongly correlated to depth distribution of the measurements and thus may in some cases be as large as $0.2^{\circ} \mathrm{C}$, though it is generally on the order of $0.05^{\circ}-0.1^{\circ} \mathrm{C}$, even for sparse historical data. Since the AAIW salinity minimum is pronounced (Figs. 1 and 3 ) and only a relative $S$ minimum is necessary for this method, the historically larger errors in $S$ have little impact on this analysis. Historical temperature measurements are likely to be accurate to at least $0.1^{\circ} \mathrm{C}$, or even $0.01^{\circ} \mathrm{C}$ in some cases.

\section{AAIW salinity minimum properties and trends}

Aspects of the AAIW salinity minimum and its variability are clear in $\theta-S$ diagrams in regions that have been sampled repeatedly by ship-based and Argo float CTDs (Fig. 3). In all three regions illustrated, the AAIW core $\theta$ generally shifts from colder to warmer (and $\sigma_{\theta}$ from denser to lighter) over the time periods sampled. Changes of AAIW core $S$ are more variable in space and time. The AAIW core $\theta$ increase results in the dipole pattern reviewed in section 1-with cooling and freshening on isopycnals lighter than the AAIW core, and warming and salinification on denser isopycnals. Comparing the trend on isopycnals (Fig. 3, dotted gray lines) between historical hydrographic profiles (color) and the Argo climatology (black) elucidates this pattern. The region shown in the South Atlantic Ocean (Fig. 3a) indicates a warming of up to $1^{\circ} \mathrm{C}$ since the 1970s. The Pacific region farther to the south (Fig. 3c) shows a stronger AAIW core warming than that to the north (Fig. 3b), though AAIW core $\theta$ increases since the early 1990s are on the order of $0.25^{\circ} \mathrm{C}$ at all three locations. To determine 

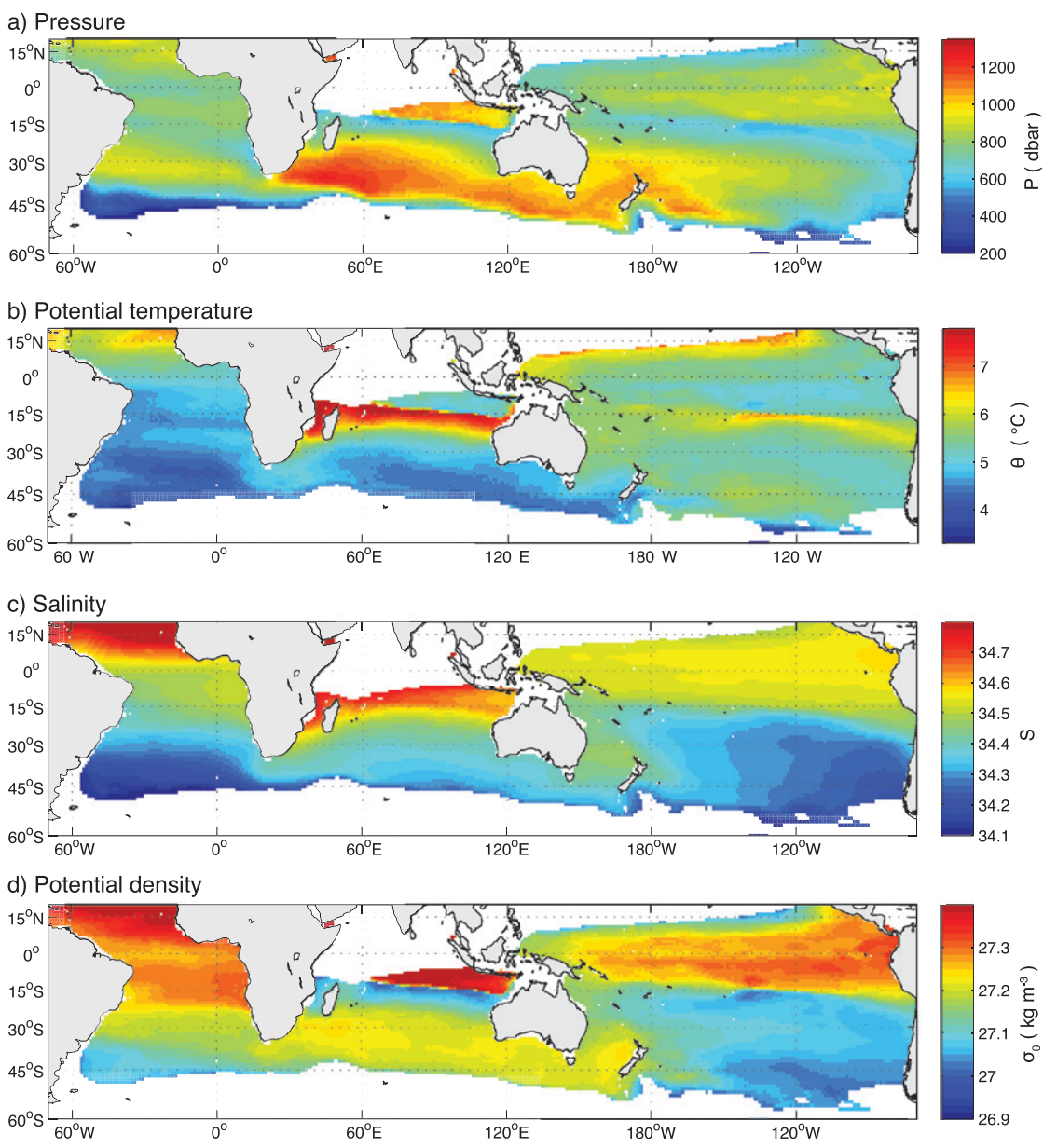

FIG. 4. Maps of (a) pressure, (b) potential temperature, (c) salinity, and (d) potential density at the AAIW core (salinity minimum) of the Argo climatology.

better how these warming trends vary by location since the mid-1970s (or somewhat later depending on the local availability of data-see Fig. 2) we map them globally.

The influence of AAIW plausibly ranges in thickness from 500 to $1000 \mathrm{~m}$, depending on ocean and latitude. Here we analyze trends in the properties of the AAIW core, its $S$ minimum, since the mid-1970s. This feature is well defined, least mixed with waters of different origin, and easy to locate within data profiles. As detailed above, we use the Argo float climatology for reference values for the AAIW core properties determined from ship-based CTD data, since the Argo float array sampling of $\theta$ and $S$ in the upper $2 \mathrm{~km}$ of the Southern Hemisphere oceans is unsurpassed.

\section{a. Brief overview of the climatological state}

The climatological AAIW core is found within $500<$ $P<1400$ dbar, varying by location (Fig. 4a). This feature starts just north of the ACC and spreads northward from there to at least $20^{\circ} \mathrm{S}$, depending on longitude.
In the Atlantic the AAIW core has a maximum $P$ of $\sim 900 \mathrm{dbar}$ at $30^{\circ} \mathrm{S}$ before rising to $750 \mathrm{dbar}$ around the equator $\left(20^{\circ} \mathrm{S}-10^{\circ} \mathrm{N}\right)$ and deepening again in the North Atlantic (Figs. 1a and 4a). The AAIW core becomes denser in more northerly latitudes by entrainment and mixing, with its $\sigma_{\theta}$ increasing by $0.2-0.3 \mathrm{~kg} \mathrm{~m}^{-3}$ from $50^{\circ} \mathrm{S}$ to $20^{\circ} \mathrm{N}$ (Fig. $4 \mathrm{~d}$ ). In subtropical latitudes a zonal gradient of AAIW core density is distinguishable, with higher values in the eastern Atlantic. All northward and eastward density increases in the Atlantic are mainly due to salinification of the AAIW core that overcomes the reduction in density from minor warming (Figs. 4b-d).

The Indian Ocean AAIW core is found within $1200<$ $P<1400$ dbar a few degrees north of the ACC and shoals to $600 \mathrm{dbar}$ by around $20^{\circ} \mathrm{S}$ (Fig. 4a). North of $20^{\circ} \mathrm{S}$ salty northern Indian Ocean waters dominate and erode the AAIW $S$ minimum completely after briefly deepening it to $1000 \mathrm{~m}$. The Indian Ocean AAIW core is found near $\sigma_{\theta}=27.2 \mathrm{~kg} \mathrm{~m}^{-3}$ south of $30^{\circ} \mathrm{S}$ (Figs. 1b-c and $4 d)$. It trends toward lighter densities northward of that 
latitude before increasing abruptly to $\sigma_{\theta} \sim 27.4 \mathrm{~kg} \mathrm{~m}^{-3}$ just prior to disappearing completely. This behavior reflects the strong regional influence of warm and salty northern Indian Ocean waters.

Within the Pacific Ocean the AAIW core at $26.98<$ $\sigma_{\theta}<27.8 \mathrm{~kg} \mathrm{~m}^{-3}$ can be found from just north of the ACC to $10^{\circ}-20^{\circ} \mathrm{N}$ (Figs. 4a,d). While the tropical salinity minimum in the Atlantic originates solely from AAIW, the Pacific tropical salinity minimum has contributions from AAIW from the south and North Pacific Intermediate Water (Talley 1993) from the north. Since this study focuses on the AAIW core we restrict further discussion and analyses in the Pacific to south of $20^{\circ}$ $15^{\circ} \mathrm{S}$, to exclude the tropical salinity minimum that is found at $\sigma_{\theta}>27.2 \mathrm{~kg} \mathrm{~m}^{-3}$ (Figs. 1c-e and 4d).

In the Atlantic and Indian Oceans, $\theta$ and $S$ distributions at the AAIW core tend to be well correlated, with opposing influences on density (Figs. $4 \mathrm{~b}-\mathrm{d}$ ). This tendency does not hold in the Pacific Ocean. There the AAIW core $S$ increases from the east toward the west, with its lowest values around 34.1 in the vicinity of the Humboldt Current off the west coast of South America, and increasing to above 34.4 close to New Zealand. The Pacific AAIW core $\theta$ distribution is coldest in the east as well, but with a cold tongue reaching westward across the Pacific Ocean around $30^{\circ} \mathrm{S}$ created by warmer values to the south (Fig. 4b). This distribution of $\theta-S$ properties appears similar to the pattern of AAIW core $P$ (Fig. 4a), which shows a shoaling extending northward along the west coast of South America to about $30^{\circ} \mathrm{S}$, and then extending westward and slightly northward across the Pacific. The AAIW core $P$ is significantly deeper in the central and western Pacific Ocean than elsewhere in the Pacific. Finally, the AAIW core $\sigma_{\theta}$ is lightest in the central and east South Pacific Ocean and densest in the west.

\section{b. Trends since the mid-1970s}

Maps of linear temporal trends in anomalies of AAIW core properties from ship-based CTD data relative to the Argo climatology show clear circumpolar patterns of shoaling, warming, and density reduction, with more variable salinity changes (Fig. 5). While the ends of the trend estimates are anchored by the Argo climatology in 2009, along with recent hydrographic sections in a few locations, the starts of the trend estimates vary regionally between 15 and $>35$ yr prior to 2009 depending on CTD sampling (Fig. 2). The shortest time periods of 15-20 yr are located in a small portion of the southeast Pacific. The time span analyzed is more than $20 \mathrm{yr}$ in the tropical western Pacific and eastern Indian Oceans south of about $30^{\circ} \mathrm{S}$, and increases to more than $35 \mathrm{yr}$ in the Atlantic north of $20^{\circ}-15^{\circ} \mathrm{S}$ and in much of the western and central South Pacific. Thus these trends are estimated over varying times, depending on when CTD sampling began in the region. This mapping of trends with varying starting periods assumes a generally linear signal over the sampling period. The assumption appears to hold for AAIW core $\theta$ in the relatively well-sampled regions analyzed (Fig. 3, marks on $y$ axes), whereas again the AAIW core $S$ appears more variable (Fig. 3, marks on $x$ axes). We revisit this assumption in section $3 \mathrm{c}$.

A widespread shoaling trend is obvious south of $30^{\circ} \mathrm{S}$ in all ocean basins (Fig. 5a). The shoaling trend approaches $5 \mathrm{dbar} \mathrm{yr}^{-1}$ around the AAIW formation regions of the southeast Pacific and South Atlantic, and is weakest around the ACC in the Indian Ocean. The trend eases in all oceans increasingly northward of the ACC, where the climatological AAIW core $P$ deepens (Fig. 4a). At many longitudes the trend in AAIW core $P$ changes sign around $30^{\circ} \mathrm{S}$. In the South Pacific Ocean the AAIW core $P$ shoaling is most pronounced in the central and eastern regions, with less significant and smaller shoaling trends in the west. In the Pacific the shoaling stops abruptly at the southern edge of the tropical salinity minimum. Similar to the Atlantic, a stronger shoaling is observed in Pacific Ocean regions with a climatological AAIW core $P<500$ dbar.

The multidecadal warming trend of AAIW core $\theta$ is very strong and statistically significant in most locations south of around $20^{\circ} \mathrm{S}$ (Fig. 5b). Maximum trends of around $20 \times 10^{-3 \circ} \mathrm{C} \mathrm{yr}^{-1}$ are estimated in much of the South Atlantic Ocean between the ACC and $30^{\circ} \mathrm{S}$ as well as the eastern South Pacific in the same latitude range. In the Pacific Ocean the trend becomes more patchy north of $20^{\circ} \mathrm{S}$ in the area of the tropical salinity minimum, often reversing sign to cooling, whereas in the Atlantic the trend persists northward all the way to $20^{\circ} \mathrm{N}$, albeit weaker and reversing sign in a small portion of the southeastern tropical Atlantic. The trend is still toward warming in the western South Pacific and eastern South Indian Oceans, although it is not as strong near the ACC as elsewhere, and not always statistically significant.

In contrast to the strong, large-scale, and statistically significant warming and shoaling trends found at the AAIW core between $30^{\circ} \mathrm{S}$ and the ACC, AAIW core $S$ trends vary by region in that latitude band (Fig. 5c). A long-term freshening is found in the southwest Atlantic, southeast Pacific, and south-central Indian Oceans, with salinification south of Africa and Australia. As warned earlier, fitting a linear trend to a variable signal in core AAIW $S$ (e.g., Fig. 3, marks on $x$ axes) only sparsely sampled may alias these results. North of $30^{\circ} \mathrm{S}$, the trend is mostly toward weak salinification, with only a few small areas of freshening.

In terms of their relative contributions to AAIW core $\sigma_{\theta}$ trends, the strong and large-scale warming generally 

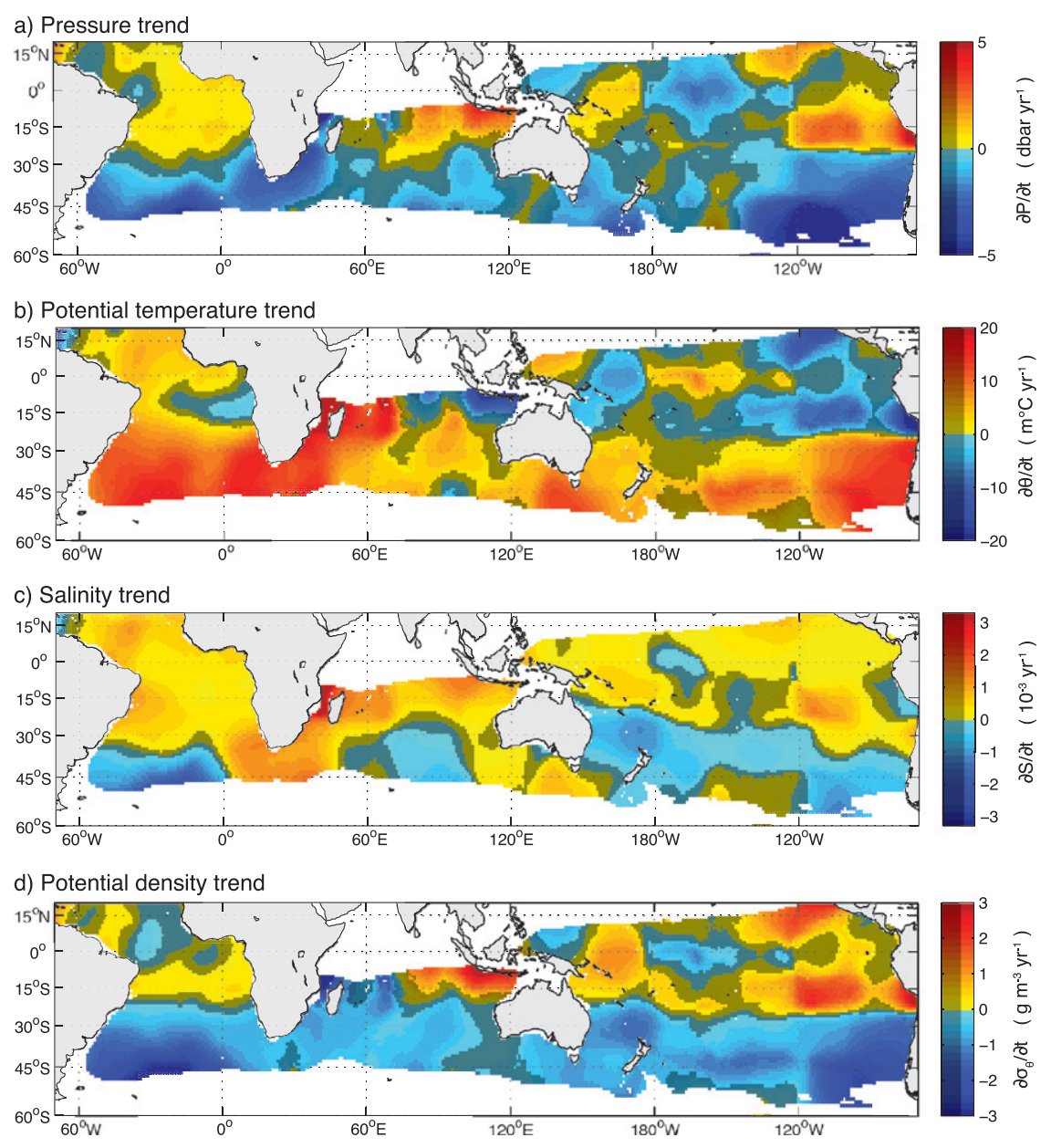

FIG. 5. Maps of linear trends over the time period of ship-based and Argo float CTD sampling for (a) pressure, (b) potential temperature, (c) salinity, and (d) potential density. Regions where trends are not significantly different from zero at the $95 \%$ confidence level are shaded dark.

dominates the smaller and patchier salinity changes, resulting in a broad reduction in AAIW core $\sigma_{\theta}$ (Fig. $5 \mathrm{~d})$. The pattern of the lightening density trends is pretty well correlated with the warming trend pattern (Fig. 5b).

Zonal averages of AAIW core property trends in each ocean basin are one way of condensing the large-scale signals and assessing their statistical significance (Fig. 6). The reader should bear in mind that this analysis obscures the zonal structure in property trends of the basins, especially the contrast between the eastern and western South Pacific Ocean (Fig. 5). Nonetheless, trends of shoaling $P$ (Fig. 6a), warming $\theta$ (Fig. 6b), and reductions in $\sigma_{\theta}$ (Fig. $6 \mathrm{~d}$ ) at the core of the AAIW are strongest close to the formation latitude, just north of the ACC, and are statistically significantly different from zero at $95 \%$ confidence in all basins at least as far north as $25^{\circ} \mathrm{S}$ for $P$ and $\theta$, and $30^{\circ} \mathrm{S}$ for $\sigma_{\theta}$. In contrast, the zonally averaged $S$ trends change sign from basin to basin and have larger confidence intervals, with only an Atlantic Ocean freshening trend and an Indian Ocean salinification trend both being significantly different from zero south of $45^{\circ} \mathrm{S}$ (Fig. 6c). There is also a tendency toward a slight but statistically significant salinification north of $35^{\circ}-25^{\circ} \mathrm{S}$ in all three basins.

\section{c. Temperature variability since the mid-1920s}

The AAIW core property trends estimated from shipbased and Argo float CTD data presented above do not address the degree of decadal variability, except indirectly through estimates of their statistical significance. As noted above, repeat CTD data from relatively frequently sampled areas near AAIW formation regions suggest a generally monotonic trend in AAIW core $\theta$ (Fig. 3, marks on $y$ axis) but more variable changes in AAIW core $S$ (Fig. 3, marks on $x$ axis) over the last few decades.

Since regions with repeat hydrographic measurements over several decades are limited in the Southern 
a) Pressure trend

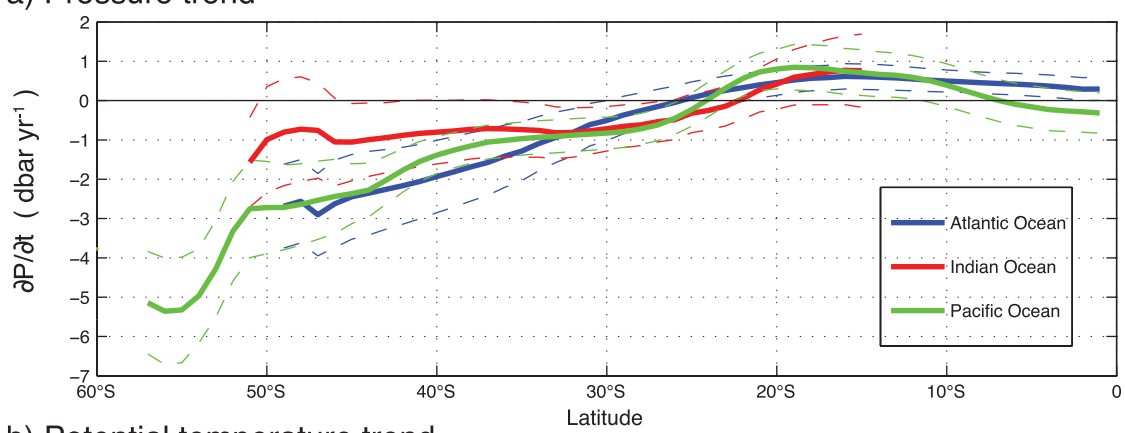

b) Potential temperature trend

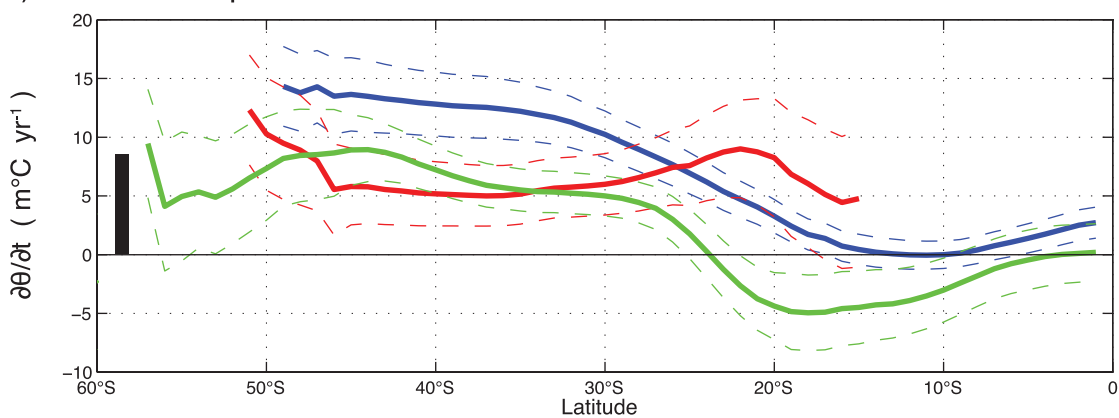

c) Salinity trend

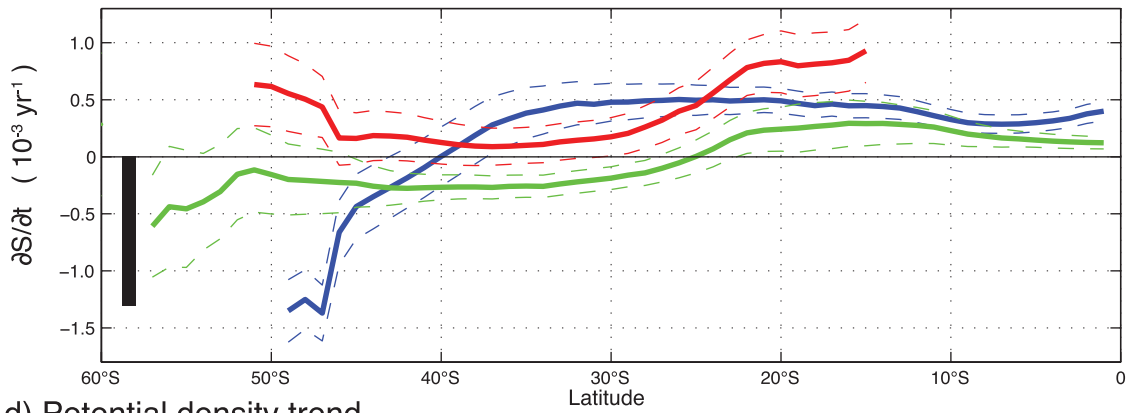

d) Potential density trend

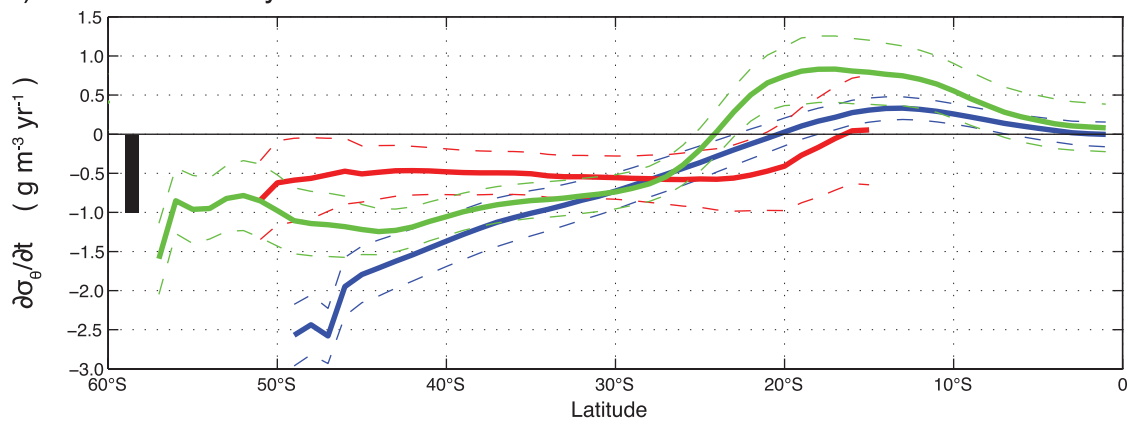

FIG. 6. Zonal mean temporal trends at the AAIW core (salinity minimum) estimated over the CTD sampled time period of (a) pressure, (b) potential temperature, (c) salinity, and (d) potential density in the three ocean basins (color-coded thick lines) with $95 \%$ confidence limits (dashed lines). Black bars indicate relative influences of potential temperature and salinity trends on the density trend at $S=34.4$ and $\theta=5^{\circ} \mathrm{C}$. Each bar corresponds to a change of $-1\left(\mathrm{~g} \mathrm{~m}^{-3}\right) \mathrm{yr}^{-1}$ in density.

Hemisphere, we take a different approach and analyze statistics for historical AAIW core $\theta$ anomalies in each ocean basin at biennial temporal resolution over a southern latitude band from $50-40^{\circ} \mathrm{S}$ (Fig. 7, blue symbols) and a northern one from 30-20 ${ }^{\circ}$ S (Fig. 7, yellow symbols), considering bottle and CTD data separately. Statistics for the latitude band $40^{\circ}-30^{\circ} \mathrm{S}$ (not shown) are very similar to those shown for $50-40^{\circ} \mathrm{S}$ in all three ocean basins, 
consistent with the results of small meridional variations in post- 1975 AAIW core $\theta$ trends from $50^{\circ}$ to $30^{\circ} \mathrm{S}$ (Fig. 6b).

Including bottle data extends the analysis back to $\sim 1960$ in the Indian and Pacific Oceans and as far back as 1925 in the Atlantic, albeit with temporal gaps and sparse spatial coverage from 1925 to 1955 (Fig. 7, small maps). The relatively well-sampled decades between 1955 and 1995 indicate biennial temporal variability on the order of $0.2^{\circ} \mathrm{C}$ (perhaps less in the Indian and Pacific Oceans and more in the southern Atlantic Ocean) for AAIW core $\theta$ anomalies within each latitude band in all ocean basins.

The biennial median CTD-derived AAIW core $\theta$ anomalies show a roughly linear warming trend for the southern latitude band in all three oceans since around 1975 (the earliest starting time for Figs. 5 and 6 trend estimates), with only moderate variability about that trend (Fig. 7). The Atlantic AAIW core $\theta$ values (Fig. 7a) in the southern latitude band have warmed fairly steadily by about $0.7^{\circ} \mathrm{C}$ since 1955 and appear to be warmer around 2009 than at any sampled time since 1925 . The median CTD-derived warming in the southern band is at a rate of about $13 \times 10^{-30} \mathrm{C} \mathrm{yr}^{-1}$, which is on the same order as the warming derived for the zonal average of the mapped fields in the Atlantic Ocean at those latitudes (Figs. 5b and $6 \mathrm{~b}$ ). The results farther from the AAIW source, in the northern latitude band, show a similar pattern with reduced magnitude since 1980. However, for 1955-75, AAIW core $\theta$ values in the northern band of the Atlantic Ocean are close to modern day levels or above, in contrast with the warming trend found in the analysis of more recent CTD data (Figs. 5b and 6b). The Indian Ocean (Fig. 7b) shows a significant smaller warming trend in the southern band for the period of CTD data and no trend for the northern band in the same period, consistent with the results above (Figs. $5 \mathrm{~b}$ and $6 \mathrm{~b}$ ). Bottle data confirm this trend since the late 1950s, though with statistical significance only for the northern band, that shows little to no trend for the period of CTD data. The Pacific Ocean (Fig. 7c) shows a trend of $0.4^{\circ} \mathrm{C}$ since 1960 in both zonal bands, consistent over the periods of bottle and CTD data.

Biennial averages of core AAIW $P$ anomalies (not shown) computed in each ocean basin support a general shoaling trend for the period of CTD data in all three basins (Figs. 5a and 6a). However, bottle data $P$ anomalies exhibit significantly larger variability (perhaps owing to measurement noise) than do bottle data $\theta$ anomalies relative to CTD data. The bottle $P$ anomalies have variable signs for the different zonal bands and oceans, with large IQR ranges that span zero for the vast majority of biennials.
The simple statistical analysis presented here is definitely subject to spatial biases in sampling within each basin (Fig. 7, small maps). Prior to 1945 all data are confined to the Atlantic Ocean, with the oldest data being from the 1925-27 South Atlantic Meteor expedition (Wüst 1936, 1-288). During the decade around World War II there are very few profiles at all. The period of $1955-85$ is relatively well sampled in all ocean basins, except for the Indian Ocean in the decades prior to and following the International Indian Ocean Expedition in the early 1960s (Wyrtki 1971). From 1985 to 95, including the height of the globally oriented World Ocean Circulation Experiment (WOCE), all three basins are well sampled. Ship-based CTD data coverage is sparse after 1995, when WOCE wound down, with only widely separated sections available, though these few sections do confirm the AAIW core property estimates derived from the Argo float climatology (Fig. 7).

The reliability of bottle data for the purposes of this study can be assessed by examining the temporal continuity of biennial averages of bottle and CTD data, since the latitude band statistics for the two different measurement types do have some overlap in the Atlantic and Pacific (Fig. 7). Aside from the large shift from positive to negative anomalies in the northern latitude band in the Atlantic during the transition from bottle to CTD data, the time series do not exhibit large changes at this switch. Even during that large shift the bottle data averages have very large interquartile ranges. The ranges between first and third quartiles for the biennial bottle data statistics are often larger than those for the CTD data, and their temporal variability is sometimes larger as well, both perhaps reflecting increased uncertainty of the individual bottle-derived $\theta-S$ profiles. Nevertheless, the bottle-derived AAIW core $\theta$ anomalies show the exceptional nature of the long-term warming in all areas except the northern latitude band in the Atlantic, with median anomalies generally below modern conditions and even their third quartiles below or close to modern conditions.

\section{Discussion}

As noted in section 1, there have been many investigations of $\theta-S$ changes on isopycnals and isobars that suggest decadal or longer-scale changes extending into the AAIW. Here we address AAIW variability by a global analysis of temporal trends and variability at the AAIW core, defined by its local vertical salinity minimum. We use a climatology constructed from modern Argo float CTD data as a reference from which we estimate property anomalies at the AAIW core with both ship-based CTD data extending back to the mid-1970s 
a) Atlantic Ocean potential temperature anomaly

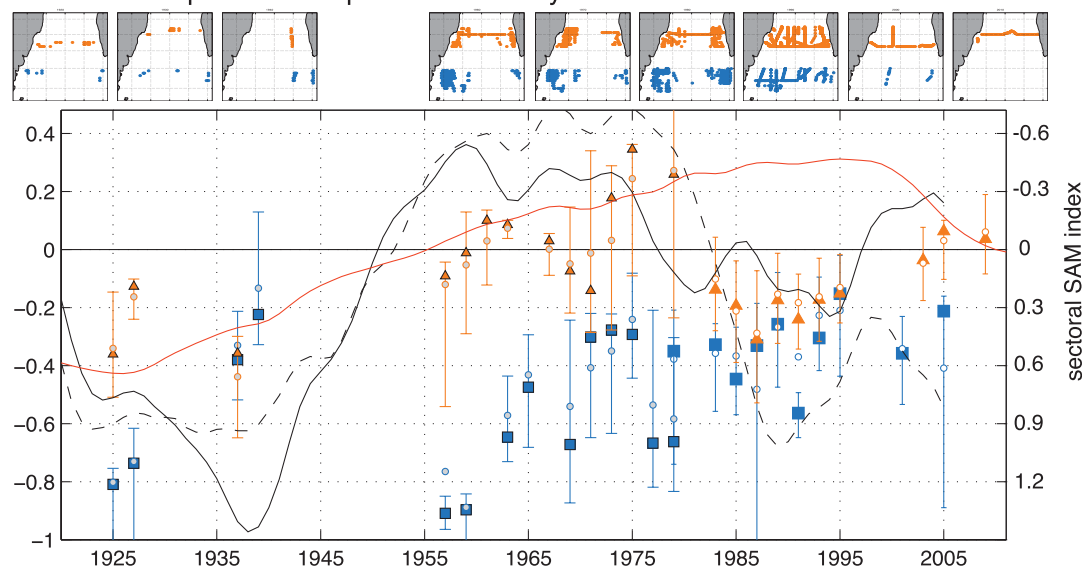

b) Indian Ocean potential temperature anomaly

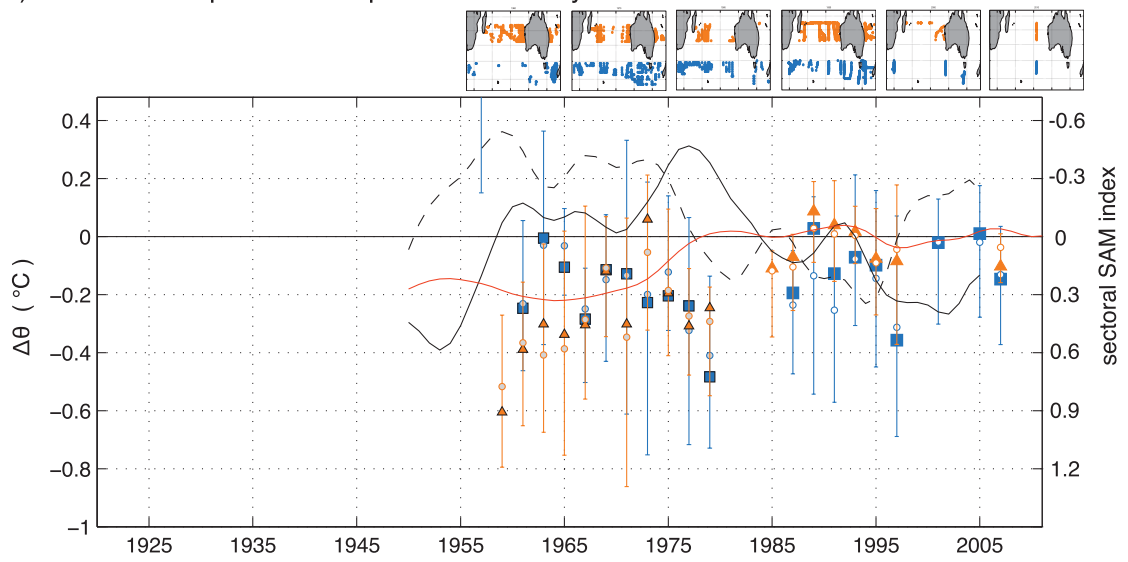

c) Pacific Ocean potential temperature anomaly

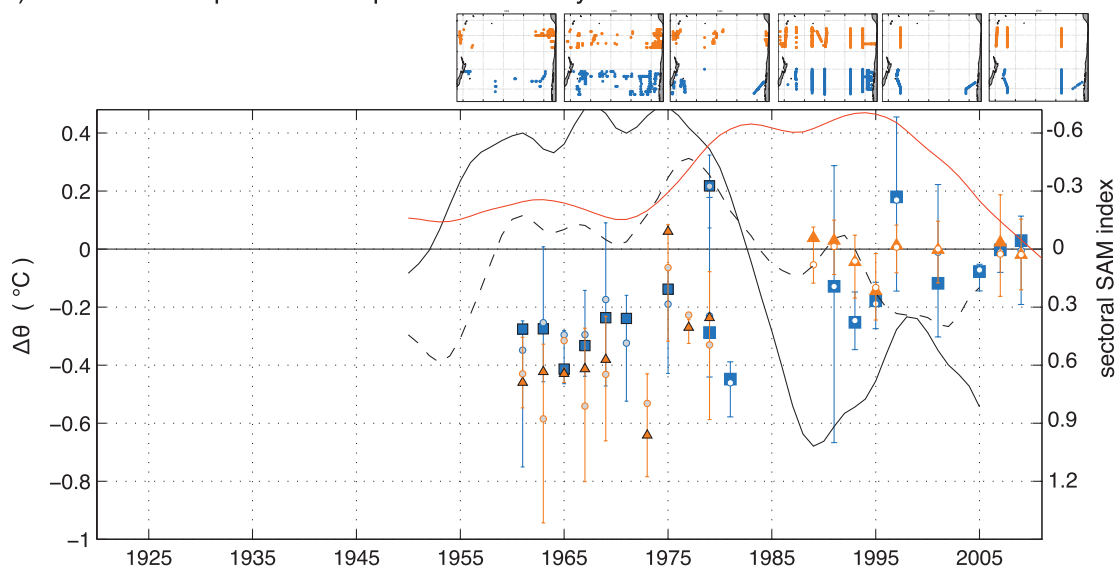

FIG. 7. Median AAIW core $\theta$ anomalies for the (a) Atlantic, (b) Indian, and (c) Pacific Oceans in two latitude bands: $50^{\circ}-40^{\circ} \mathrm{S}$ (blue squares) and $30^{\circ}-20^{\circ} \mathrm{S}$ (orange triangles) estimated in biennial time bins from bottle (black edges) and CTD (no edges) data with first and third quartiles (whiskers) shown for all bins with more than five data points. Potential temperature anomaly means are also indicated for bottle (gray-filled circles) and CTD (open circles) data. Sectoral winter SAM indices (Visbeck 2008 and M. Visbeck 2011, personal communication) smoothed with an 8-yr radius LOESS smoother (black line for the east and black dashed line for west boundary of each basin) with sign reversed and similarly smoothed winter $60^{\circ}-55^{\circ} \mathrm{S} \mathrm{SST}$ anomalies (red line) from the $2^{\circ} \times 2^{\circ}$ gridded NOAA extended reconstructed sea surface temperature (ERSST v3b) for each basin (Smith et al. 2008) are shown (see text for details). Small maps at the top of each figure show data locations for each basin and decade centered on 1930, $1940, \ldots, 2000$, with half-decade distributions prior to 1925 and after 2005. 
and bottle data back to the mid-1920s (at least in the Atlantic Ocean). We find large-scale multidecadal shoaling, warming, and reduction in density of the AAIW core since around the mid-1970s, with the recent warming apparently unprecedented since the beginning of observations with sufficient vertical resolution -in the southern reaches of the Atlantic Ocean since 1925, and in the Pacific and Indian Oceans since around 1960, subject to uncertainties owing to the sparse historical sampling. Salinity changes are generally small with respect to temperature changes in terms of their relative effects on density and also vary regionally. These changes are generally consistent with the bulk of changes previously reported in the literature of which we are aware.

Only a few areas in the Southern Hemisphere oceans are as well sampled in time as the regions where CTD $\theta-S$ curves illustrate monotonic multidecadal warming of the AAIW core (Fig. 3). Hence, the period over which trends in AAIW core properties (Figs. 5 and 6 ) are analyzed ends in 2009 with the Argo climatology used as a reference, or with a more recent hydrographic section, but begins at times that vary depending on location. The trends are estimated over periods as short as $15-20 \mathrm{yr}$ in limited regions and as long as 35-40 yr over somewhat larger areas, with most regions having CTD data records of intermediate length. The trends in warming, shoaling, and reduction in density of the AAIW core exhibit largescale patterns that transcend the regionally varying time periods over which the trends are estimated. Furthermore, analyzing AAIW core $\theta$ anomaly statistics in latitude bands and biennial time bins since 1975 for CTD data and since 1925 for bottle data (Fig. 7) suggests that the linear trend analysis assumption is reasonable for $\theta$ since 1975 .

The zonal mean trends of the AAIW core $\theta$ anomaly from $50^{\circ}$ to $40^{\circ} \mathrm{S}$ derived from CTD data (Fig. 6) suggest a warming of up to $0.14^{\circ} \mathrm{C} \mathrm{decade}{ }^{-1}$ in the Atlantic Ocean, around $0.08^{\circ} \mathrm{C}$ decade $^{-1}$ in the Pacific Ocean, and about $0.06^{\circ} \mathrm{C}$ decade $^{-1}$ in the Indian Ocean. A comparison of these numbers to the median anomalies since $\sim 1925$ in the same latitude band for the Atlantic (Fig. 7) indicates that they appear to represent the warming since the late 1950s but would exaggerate a centennial time-scale warming by $0.2^{\circ}-1.0^{\circ} \mathrm{C}$, since the rate of warming from $\sim 1925$ to $\sim 1955$ is much reduced compared to that after $\sim 1955$. The Indian and Pacific Oceans show little to no trend from $\sim 1960$ to the mid-1970s with values around $0.2^{\circ}$ and $0.3^{\circ} \mathrm{C}$ colder than recent values from Argo.

For the more northern latitude band of $30^{\circ}-20^{\circ} \mathrm{S}$ in the Indian and Pacific Oceans both methods lead to a warming in the order of $0.02^{\circ}-0.05^{\circ} \mathrm{C}$ decade $^{-1}$, though only on longer time scales when including the bottle data. The northern latitude band in the Atlantic Ocean behaves opposite to the general trend found in all other bands for the period 1955-80. During this period, northern band Atlantic AAIW core $\theta$ anomalies are significantly higher than directly before or after that period, at values similar to modern ones.

Because of the large IQR of bottle data, their generally sparse spatial sampling, and the different analysis procedures for bottle and CTD data, we do not use the median AAIW core $\theta$ anomaly values of Fig. 7 for fitting a linear warming trend, though they do confirm the general trend in the data since 1955 for the southern latitude band in all basins and the northern band in the Indian and Pacific Oceans, when broad-scale spatial sampling begins.

In contrast, estimated AAIW core $S$ trends since the mid-1970s are neither coherent at the large scale (Figs. 5c and $6 c$ ) nor monotonic in temporally well-sampled regions (Fig. 3), suggesting that in most regions there may be no pronounced long-term AAIW core $S$ trend, despite a strong variability on decadal time scales (Fig. 3), consistent with diverse salinity changes described in other studies mentioned in section 1. Consistent with this finding, the tendency toward reduced density of the AAIW core with time is dominated by the $\theta$ warming.

Trends in AAIW core $P$ appear to be similar to trends in AAIW core $\sigma_{\theta}$ to first order (Figs. 5 and 6). Such a result should hold in the absence of other effects given steady ocean stratification. Of course, heave in isopycnal pressures owing to changes in wind forcing (Bindoff and McDougall 2000) may play a role in determining local variations of AAIW core $P$. The analyzed patterns may be aliased by short-term variations, a likelihood supported by large variability of biennial averaged AAIW core $P$ anomalies in all basins (not shown). Despite this possible aliasing, estimated pressure trends subside more rapidly with increasing distance from the AAIW formation regions than do the trends of density (Figs. 5a,d and 6a,d). Furthermore, both trends exhibit consistent large-scale circumpolar patterns.

\section{a. Origin of trends}

The sea level pressure (SLP) index known as the Southern Annual Mode (SAM), especially in winter, and winter sea surface temperature (SST) near the AAIW formation latitudes may be related to AAIW core property variability. The winter SST ventilates the AAIW, and the SLP variations are related to wind variations, which are important regional drivers of ocean circulation and ventilation. The SAM and local SST variations have recently been suggested to influence AAIW formation (Naveira Garabato et al. 2009; Downes et al. 2010; Sallée et al. 2010a,b). Here we examine basin-averaged SST (Smith et al. 2008) from $60^{\circ}-55^{\circ} \mathrm{S}$ (Fig. 7, red lines) and sectoral winter SAM indices based on SLP variations between Antarctica and the southern ends of Africa, 
Australia, and South America (Visbeck 2008; M. Visbeck 2011, personal communication; Fig. 7, black lines). These variables generally exhibit upward trends since the mid1970s-with larger SAM variability, coincident with the observed warming, shoaling, and reduction in density of the AAIW core since that time.

In the Atlantic the winter averaged SST from $60^{\circ}$ to $55^{\circ} \mathrm{S}$ warms by $\sim 0.7^{\circ} \mathrm{C}$ from 1925 to the late 1990 s, then cools by $\sim 0.3^{\circ} \mathrm{C}$ from the late 1990 s to 2009 . The winter SST between $60^{\circ}$ and $55^{\circ} \mathrm{S}$ trends warmer from the late 1950 s to late 1990s in all three basins by the same order of magnitude as the median observed warming of the AAIW core $\theta$ anomalies from $50^{\circ}$ to $40^{\circ} \mathrm{S}$ in those basins (Fig. 7). Thus the AAIW core $\theta$ anomaly trends seem to reflect regional ocean surface warming trends from $60^{\circ}$ to $55^{\circ} \mathrm{S}$, at least for $1955-95$. This trend is stronger in the eastern Pacific and Atlantic Oceans (Gille 2008), the main formation regions of AAIW. The zonal average SST and AAIW core $\theta$ anomaly increases in the Indian Ocean are noticeably smaller than in the Atlantic and Pacific (Figs. 6 and 7). However, the drop in winter SST since late 1990s in the Pacific and Atlantic Oceans is not reflected in the AAIW core $\theta$ anomalies.

The SAM index also rises since the mid-1970s (Marshall 2003; Visbeck 2008) when the AAIW core $\theta$ anomaly warming is illuminated by CTD data (Figs. 6 and 7). In the 1920s the sectoral winter SAM indices (Fig. 7, black lines) surrounding the Atlantic have values similar to or higher than those in the 1990s, though the bottle data suggest that the AAIW core $\theta$ anomaly was significantly colder in the 1920s than in the 1990s. In all basins the sectoral winter SAM indices exhibit a trough between the 1950s and late 1970s, marking roughly three phases, with high SAM in the second and fourth quarters of the twentieth century and low SAM in the third quarter.

The Atlantic Ocean northern latitudinal band $\left(30^{\circ}-\right.$ $20^{\circ} \mathrm{S}$ ) shows AAIW core $\theta$ anomalies close to zero or positive in the third quarter of the twentieth century, which coincides with a low sectoral winter SAM index between South America and Antarctica (Fig. 7a, black dashed line) and between Africa and Antarctica (Fig. 7a, black solid line). This latitudinal band covers the pathway of warm, salty Agulhas leakage from the Indian Ocean to the Atlantic (McCarthy et al. 2011; Beal et al. 2011). An increased Agulhas leakage is proposed for poleward shift or easing of westerly winds (Beal et al. 2011), as occurs with a low SAM index. This leakage mechanism seems a possible explanation for the warm AAIW core $\theta$ anomalies in the northern latitude band of the Atlantic from 1957 to 1977.

The lack of a global coherent AAIW core $S$ change is interesting in light of expected changes in the hydrological cycle as Earth warms (i.e., more evaporation in drier locations-leading to salinification, and more precipitation in rainy areas, like the AAIW formation region-leading to freshening). These changes are seen in simulations of global warming, which suggest that this signal might be discernible over the last two decades of the twentieth century (Held and Soden 2006). Differences of maps of 2003-07 Argo data and historical 1960-89 ocean data do reveal a pattern of salty surface waters getting saltier and fresher surface waters getting fresher (Hosoda et al. 2009), as do estimates of linear trends from 1950 to 2008 (Durack and Wijffels 2010). These surface changes have been tracked into the ocean interior along density surfaces (Helm et al. 2010). However, an alternate explanation for the interior changes of a roughly uniform warming superimposed upon existing salinity patterns has also been advanced (Durack and Wijffels 2010), perhaps consistent with the lack of a coherent global change in AAIW core $S$ found here.

A warming trend at the AAIW core due to enhanced mixing or entrainment of underlying or overlying water masses is not likely, since that process would necessarily lead to an increasing trend in salinity at the AAIW core. Only the Atlantic north of $40^{\circ} \mathrm{S}$ shows a small but widespread salinification of the AAIW core, again consonant with an increase of Agulhas leakage due to the recently decreasing sectoral winter SAM index between Africa and Antarctica.

\section{b. Impacts of trends}

A warming, shoaling, and reduction in density of the AAIW core is likely to impact the ventilation of the base of the thermocline in subtropical regions, reducing the pressure and density to which subthermocline waters ventilated by AAIW are oxygenated. As a consequence of these trends, oxygen could be reduced in deep subtropical and tropical regions, where the AAIW plays a crucial role in oxygen supply. While the middepth tropical oxygen minimum zones do appear to be expanding over recent decades (Stramma et al. 2008, 2010), we are not aware of confirmation of this possible contributory mechanism.

Also, a great deal of carbon has accumulated in AAIW around the Southern Ocean in recent decades (Sabine et al. 2004; McNeil et al. 2003). This accumulation rate might change under global warming scenarios (Downes et al. 2010), and the AAIW core warming, shoaling, and reduced density might be related to such a change.

Finally, model studies suggest a downstream impact of an AAIW warming or cooling on the order of $1^{\circ} \mathrm{C}$ propagating to the North Atlantic middepth and even surface waters on time scales of several decades (Graham et al. 2011). The AAIW warming trend observed over a few decades is on the order of that imposed in this model study. 
In summary, the AAIW core around the globe south of $30^{\circ} \mathrm{S}$ is apparently currently significantly warmer than it has been in the historical record, which for our analysis extends back to the mid-1920s in the Atlantic and $\sim 1960$ in the Indian and Pacific Oceans. The one exception is the portion of the Atlantic Ocean subject to Agulhas leakage of warm, salty waters from the Indian Ocean. Data from previous times show a colder AAIW core in all three ocean basins, when they are sampled. Historical data suggest that the warming trend of the AAIW core may have intensified since the mid-1970s in the Indian and Pacific Oceans and since the mid-1950s in the southern Atlantic, similar to the winter SST around the formation latitudes of AAIW, at least until the late 1990s. The AAIW core also has shoaled significantly and become significantly less dense since the mid-1970s, but there is no strong large-scale trend in salinity at the AAIW core.

Acknowledgments. Float data used here were collected and made freely available by Argo (http://www.argo.net/), a program of the Global Ocean Observing System, and contributing national programs. Our heartfelt thanks go to all those who helped to collect, calibrate, and process Argo, WOCE, and GO-SHIP data analyzed here. Comments of two anonymous reviewers helped to improve the manuscript. The findings and conclusions in this article are those of the authors and do not necessarily reflect the views of the National Oceanic and Atmospheric Administration (NOAA). The NOAA Climate Program Office and the NOAA Office of Oceanic and Atmospheric Research supported this analysis.

\section{REFERENCES}

Aoki, S., N. L. Bindoff, and J. A. Church, 2005: Interdecadal water mass changes in the Southern Ocean between $30^{\circ} \mathrm{E}$ and $160^{\circ} \mathrm{E}$. Geophys. Res. Lett., 32, L07607, doi:10.1029/2004GL022220.

Arbic, B. K., and W. B. Owens, 2001: Climatic warming of Atlantic Intermediate Waters. J. Climate, 14, 4091-4108.

Beal, L. M., and Coauthors, 2011: On the role of the Agulhas system in ocean circulation and climate. Nature, 472, 429-436.

Bindoff, N. L., and J. A. Church, 1992: Warming of the water column in the southwest Pacific Ocean. Nature, 357, 59-62.

—_, and T. J. McDougall, 2000: Decadal changes along an Indian Ocean section at $32^{\circ} \mathrm{S}$ and their interpretation. J. Phys. Oceanogr., 30, 1207-1222.

Böning, C. W., A. Dispert, M. Visbeck, S. R. Rintoul, and F. U. Schwarzkopf, 2008: The response of the Antarctic Circumpolar Current to recent climate change. Nat. Geosci., 1, 864-869.

Cleveland, W. S., and S. J. Devlin, 1988: Locally-weighted regression: An approach to regression analysis by local fitting. J. Amer. Stat. Assoc., 83 (403), 596-610.

Defant, A., 1941: Die absolute Topographie des Pysikalischen Meeresniveaus und der Druckflächen, sowie die Wasserbewegungen im Atlantischen Ozean. Vol. 6, Wissenschaftliche Ergebnisse der Deutschen Atlantischen Expedition auf dem
Forschungs- und Vermessungsschiff Meteor, 1925-1927, de Gruyter and Co., 433 pp.

Downes, S. M., N. L. Bindoff, and S. R. Rintoul, 2010: Changes in the subduction of Southern Ocean water masses at the end of the twenty-first century in eight IPCC models. J. Climate, 23, 6526-6541.

Durack, P. J., and S. E. Wijffels, 2010: Fifty-year trends in global ocean salinities and their relationship to broad-scale warming. J. Climate, 23, 4342-4362.

Fine, R. A., 1993: Circulation of Antarctic Intermediate Water in the South Indian Ocean. Deep-Sea Res. I, 40, 2021-2042.

Gille, S. T., 2008: Decadal-scale temperature trends in the Southern Hemisphere Ocean. J. Climate, 21, 4749-4765.

Graham, J. A., D. P. Stevens, K. J. Heywood, and Z. Wang, 2011: North Atlantic climate responses to perturbations in Antarctic Intermediate Water. Climate Dyn., 37, 297-311.

Held, I. M., and B. J. Soden, 2006: Robust response of the hydrological cycle to global warming. J. Climate, 19, 56865699.

Helm, K. P., N. L. Bindoff, and J. A. Church, 2010: Changes in the global hydrological-cycle inferred from ocean salinity. Geophys. Res. Lett., 37, L18701, doi:10.1029/2010GL044222.

Hosoda, S., T. Suga, N. Shikama, and K. Mizuno, 2009: Global surface layer salinity change detected by Argo and its implication for hydrological cycle intensification. J. Oceanogr., 65, 579-586.

Johnson, G. C., and A. H. Orsi, 1997: Southwest Pacific Ocean water-mass changes between 1968/69 and 1990/91. J. Climate, 10, 306-316.

Lozier, M. S., W. B. Owens, and R. G. Curry, 1995: The climatology of the North Atlantic. Prog. Oceanogr., 36, 1-44.

Marshall, G. J., 2003: Trends in the Southern Annular Mode from observations and reanalyses. J. Climate, 16, 4134-4143.

McCarthy, G., E. McDonagh, and B. King, 2011: Decadal variability of thermocline and intermediate waters at $24^{\circ} \mathrm{S}$ in the South Atlantic. J. Phys. Oceanogr., 41, 157-165.

McCartney, M. S., 1977: Subantarctic Mode Water. A Voyage of Discovery: George Deacon 70th Anniversary Volume, M. V. Angel, Ed., Pergamon Press, 103-119.

McDonagh, E. L., H. L. Bryden, B. A. King, R. J. Sanders, S. A. Cunningham, and R. Marsh, 2005: Decadal changes in the South Indian Ocean thermocline. J. Climate, 18, 1575-1590.

McNeil, B. I., R. J. Matear, R. M. Key, J. L. Bullister, and J. L. Sarmiento, 2003: Anthropogenic $\mathrm{CO}_{2}$ uptake by the ocean based on the global chlorofluorocarbon data set. Science, 299, 235-239.

Molinelli, E. J., 1981: The Antarctic influence on Antarctic Intermediate Water. J. Mar. Res., 29, 267-293.

Naveira Garabato, A. C., L. Jullion, D. P. Stevens, K. J. Heywood, and B. A. King, 2009: Variability of Subantarctic Mode Water and Antarctic Intermediate Water in the Drake Passage during the late-twentieth and early-twenty-first centuries. $J$. Climate, 22, 3661-3688.

Piola, A. R., and D. T. Georgi, 1982: Circumpolar properties of Antarctic Intermediate Water and Subantarctic Mode Water. Deep-Sea Res., 29, 687-711.

Sabine, C. L., and Coauthors, 2004: The oceanic sink for anthropogenic $\mathrm{CO}_{2}$. Science, 305, 367-371.

Sallée, J.-B., K. G. Speer, and S. R. Rintoul, 2010a: Zonally asymmetric response of the Southern Ocean mixed-layer depth to the Southern Annular Mode. Nat. Geosci., 3, 273-279.

,,,--- and S. Wijffels, 2010b: Southern Ocean thermocline ventilation. J. Phys. Oceanogr., 40, 509-529. 
Smith, T. M., R. W. Reynolds, T. C. Peterson, and J. Lawrimore, 2008 Improvements to NOAA's historical merged land-ocean surface temperature analysis (1880-2006). J. Climate, 21, 2283-2296.

Stark, S., R. A. Wood, and H. T. Banks, 2006: Reevaluating the causes of observed changes in Indian Ocean water masses. J. Climate, 19, 4075-4086.

Stramma, L., G. C. Johnson, J. Sprintall, and V. Mohrholz, 2008: Expanding oxygen-minimum zones in the tropical oceans. Science, 320, 655-658.

—, S. Schmidtko, L. A. Levin, and G. C. Johnson, 2010: Ocean oxygen minima expansions and their biological impacts. Deep Sea Res. I, 57, 587-595.

Taft, B. A., 1963: Distribution of salinity and dissolved oxygen on surfaces of uniform potential specific volume in the South Atlantic, South Pacific and Indian Oceans. J. Mar. Res., 21, 129-146.

Talley, L. D., 1993: Distribution and formation of North Pacific Intermediate Water. J. Phys. Oceanogr., 23, 517-537.
1996: Antarctic Intermediate Water in the South Atlantic. The South Atlantic: Present and Past Circulation, G. Wefer et al., Eds., Springer-Verlag, 219-238.

Tsuchiya, M., 1989: Circulation of the Antarctic Intermediate Water in the North Atlantic Ocean. J. Mar. Res., 47, 747-755.

Visbeck, M., 2008: A station-based Southern Annular Mode index from 1884 to 2005. J. Climate, 22, 940-950.

Wong, A. P. S., N. L. Bindoff, and J. A. Church, 2001: Freshwater and heat changes in the North and South Pacific Oceans between the 1960s and 1985-94. J. Climate, 14, 1613-1633.

Wüst, G., 1936: Die Vertikalschnitte der Temperatur, des Salzgehaltes und der Dichte. Vol. 5 (Suppl.), Wissenschaftliche Ergebnisse der Deutschen Atlantischen Expedition auf dem Forschungsund Vermessungsschiff Meteor, 1925-1927, Walter de Gruyter and Co., $340 \mathrm{pp}$.

Wyrtki, K., 1971: Oceanographic Atlas of the International Indian Ocean Expedition. National Science Foundation Publ. OCE/ NSF 86-00-001, 531 pp. 